\title{
A Semi-Parametric Factor Model of Interest Rates and Tests of the Affine Term Structure
}

\author{
Eric Ghysels \\ Pennsylvania State University and CIRANO \\ Serena Ng \\ Boston College
}

September 1997

\begin{abstract}
Many continuous time term structure of interest rate models assume a factor structure where the drift and volatility functions are affine functions of the state variable process. These models involve very specific parametric choices of factors and functional specifications of the drift and volatility. Moreover, under the affine term structure restrictions not all factors necessarily affect interest rates at all maturities simultaneously. This class of so called affine models covers a wide variety of existing empirical as well as theoretical models in the literature. In this paper we take a very agnostic approach to the specification of these diffusion functions and test implications of the affine term structure restrictions. We do not test a specific model among the class of affine models per se. Instead, the affine term structure restrictions we test are based on the derivatives of the responses of interest rates to the factors. We also test how many and which factors affect a particular rate. These tests are conducted within a framework which models interest rates as functions of "fundamental" factors, and the responses of interest rates to these factors are estimated with non-parametric methods. We consider two sets of factors, one based on key macroeconomic variables, and one based on interest rate spreads. In general, despite their common use we find that the empirical evidence does not support the restrictions imposed by affine models. Besides testing the affine structure restrictions we also uncover a set of fundamental factors which appear remarkably robust in explaining interest rate dynamics at the long and short maturities we consider.
\end{abstract}

We would like to thank the invaluable comments of three referees who helped us improve our paper. An early version of the paper was circulated under the title "A Semi-Parametric Factor Model for Interest Rates" and appeared as CIRANO discussion paper 96s-18. Correspondence addresses: Eric Ghysels, Department of Economics, Pennsylvania State University, 523 Kern Graduate Building, University Park, PA 16802, e-mail: eghysels@psu.edu, Serena Ng, Department of Economics, Boston College, Chestnut Hill MA 02167, e-mail: serena.ng@bc.edu. 


\section{Introduction}

Understanding the dynamics of interest rates and the term structure has important implications for issues as diverse as real economic activity, monetary policy, pricing of interest rate derivative securities and public debt financing. It is therefore not surprising that the study of interest rates occupies a prominent place in theoretical and empirical finance as well as macroeconomics. The continuous flow of research papers suggesting new ways to capture the complexity of the dynamics in the conditional mean and variance of interest rates reveals that the literature is still in search of an adequate theoretical and empirical set of models. In response to this situation a number of recent papers have surfaced abandoning the traditional parametric models and proposing a nonparametric approach to study interest rates and the term structure. Examples of such work include Aït-Sahalia (1996 a,b), Conley et al. (1996), Gallant and Tauchen (1996), Stanton (1997) and Tauchen (1996).

The most commonly used term structure models are factor models with an affine structure where the drift and volatility functions are affine functions of the state variable process. This in turn imposes restrictions on the response of interest rates of different maturities to the factors. This paper proposes a semi-parametric procedure to model interest rates. Our analysis is different from previous work in the literature in two respects. First, we test the restrictions imposed by the affine term structure model without a priori parametric functional form restrictions. Therefore, we are able to test restrictions pertaining to the general class of affine structure models. Second, in addition to considering interest rates as factors, we consider an alternative set of factors that are based on macroeconomic conditions in the economy. More specifically, we construct factors as linear functionals of key economic time series but in a way that they have a straightforward economic interpretation. Hence they do not have the drawback of principal component or latent factors which often do not have a direct interpretation.

Our semi-parametric analysis proceeds in two steps. We first identify factors without assuming knowledge of the response function of interest rates to the factors. ${ }^{1}$ Once the factors are identified, we proceed with estimating the response function using non-parametric methods. There is an obvious appeal to this two step procedure. While estimation of factor models is not uncommon in parametric models following, for instance, the classical paper by Cox, Ingersoll and Ross (1985) (henceforth CIR) and others, many of the strong distributional assumptions of linearity and normality are relaxed in our semi-parametric setting.

\footnotetext{
${ }^{1}$ The variables comprising each factor is weighted by estimates of Average Derivatives developed in Härdle and Stoker (1989) and Powell, Stock and Stoker (1989). Because the Average Derivative Estimator is a non-parametric estimator, the weights used to construct the factors are estimated without imposing strong distributional assumptions or imposing linearity.
} 
The results in our paper show that despite the widespread use of the affine term structure framework (see Duffie and Kan (1996) and references therein), it does not stand up very well empirically. Indeed, we find strong evidence against the set of restrictions implied by the general class of affine structure models. While others such as Aït-Sahalia (1996 b), Andersen and Lund (1996), Chan et al. (1992), Conley et al. (1996), Gallant and Tauchen (1996), Stanton (1997) and Tauchen (1996) also reported strong rejections of specific affine models such as the well-known affine model of CIR, our analysis differs from these works in that we do not test any specific affine model. Instead we rely on a general set of restrictions imposed by affine structures on the conditional mean and variance of interest rates.

The rest of the paper is structured as follows. In section 2 we discuss the multi-factor term structure models which motivates our empirical work. Estimation of the factors and the econometric model used to test the affine term structure restrictions are discussed in section 3 and 4 . The empirical results are presented in section 5. We use monthly zero coupon bond data for three maturities constructed from three interest rate series, a one-month T-bill, a five-year government bond and a ten-year one. Conclusions appear in section 6 .

\section{Multi-factor Term Structure Models}

It is quite common to use parametric factor models for interest rates and their term structure. The early models, like Vasicek (1977), Courtadon (1982) and Cox, Ingersoll and Ross (1985), were various types of single factor continuous time models for the short term rate $r_{t}$. In recent years multifactor models became more common. For instance, Heath, Jarrow and Morton (1992) (henceforth HJM) present a unifying theory for valuing contingent claims under a stochastic continuous time multi-factor term structure of interest rates. Duffie and Kan (1996) also proposed what can be viewed as a multi-factor Markov parameterization of the HJM model and many specific cases have been studied both theoretically and empirically. ${ }^{2}$ The appeal of the Duffie and Kan model and several of its special cases is that the factors are observable. This greatly simplifies the task of model specification, as latent factor models are far more challenging to deal with.

In this paper we will follow the tradition of assuming that factors are observable. Let us suppose for the moment that the $K$-dimensional factor state variable process is denoted by $z_{t}$ and start from the typical stochastic differential equation setup: ${ }^{3}$

\footnotetext{
${ }^{2}$ The HJM model, placed in a Markovian setting, has the entire yield curve as a state variable. The Duffie and Kan model is a finite-dimensional state space model.

${ }^{3}$ We follow the notation of Duffie and Kan (1996) here and omit the technical regularity conditions which are discussed at length in their paper.
} 


$$
d z_{t}=\nu_{z}\left(z_{t} ; \beta\right) d t+\sigma_{z}\left(z_{t} ; \beta\right) d W_{t}^{*}
$$

Given the specification of the factors one assumes that the market price at time $t$ of zero coupon bonds maturing at time $t+\tau$ is given by $f\left(z_{t}, \tau\right)$ and the so-called short-rate process $r$ is defined by:

$$
r(z)=\lim _{\tau \downarrow 0} \frac{-\log f(z, \tau)}{\tau} .
$$

Following Harrison and Kreps (1979) and Harrison and Pliska (1981) we know that under suitable regularity conditions absence of arbitrage is equivalent with the existence of a risk-neutral martingale measure $Q$. Under this measure the laws of motion of the factor process in (1) take the following form:

$$
d z_{t}=\mu_{z}\left(z_{t} ; \beta\right) d t+\sigma_{z}\left(z_{t} ; \beta\right) d W_{t}
$$

where $W_{t}=\left(W_{1 t}, \ldots, W_{K t}\right)$ is a standard Brownian motion in $R^{K}, \mu_{z}\left(z_{t} ; \beta\right)$ a $K \times 1$ vector and $\sigma_{z}\left(z_{t} ; \beta\right)$ a $K \times K$ matrix. Moreover, under the $Q$ measure the short-rate process and the zero coupon bonds satisfy:

$$
f\left(z_{t}, T-t\right)=E_{Q}\left[\exp \left(-\int_{t}^{T} r\left(z_{s}\right) d s\right) \mid z_{t}\right]
$$

almost surely for $0 \leq t \leq T \leq \infty$. When we denote $r_{\tau t}\left(z_{t}\right)=\log f\left(z_{t}, \tau\right)$ then from Itô's lemma we have that:

$$
d r_{\tau t}=\tilde{\mu}_{z}\left(z_{t} ; \beta\right) d t+\exp \left(-r_{\tau t}\right) f_{z} \sigma_{z}\left(z_{t} ; \beta\right) d W_{t}
$$

where $\tilde{\mu}_{z}\left(z_{t} ; \beta\right)=\left[\exp \left(-r_{\tau t}\right) f_{z} \mu_{z}\left(z_{t} ; \beta\right)+.5\left(\exp \left(-r_{\tau t}\right)\left(f_{z z}\right) \sigma_{z}\left(z_{t} ; \beta\right)\right)\right]$. Equations (2), (4) and (5) represent a generic, complete markets, multi-factor Markov term structure model. Often the $K$ factors are chosen to be a set of interest rates with distinct maturities and the cross-maturity restrictions are exploited for estimation and interpolation. Under standard regularity conditions there is a one-to-one mapping between the set of $K$ fundamental factors and the $K$ interest rates of distinct maturity so that the choice of maturities is not essential. In the case of $K=1$ it suffices to use one interest rate to model the entire term structure. Practitioners often "calibrate" the model for a number of interest rates at fixed maturities at least equal in number to the dimension of $z_{t}$, and it is common practice to decompose changes in the term structure into "level", "slope" and "curvature" factors. Dai and Singleton (1997) discuss in detail the over-identifying restrictions imposed on the joint distribution of bond yields by affine interest rate models and show the various re-parameterizations and normalizations that exist between alternative representations of the factors. ${ }^{4}$

\footnotetext{
${ }^{4}$ It should be noted that Dai and Singleton (1997) focus on the class of affine term structure models with $\nu_{z}\left(z_{t} ; \beta\right)$ and $\sigma_{z}\left(z_{t} ; \beta\right)$ linear in $z_{t}$. Further discussion on this will follow later.
} 
Needless to say, only carefully chosen parametric forms for $\mu_{z}(., \beta), \sigma_{z}(., \beta)$ and the function $f$ will satisfy (3) and (4). In parametric factor models, convenient restrictions are often chosen so that the models yield closed form solutions for pricing derivative securities. For example, single factor models typically involve a linear mean-reverting drift set $\mu_{z}\left(z_{t} ; \beta\right)=\beta_{1}\left(\beta_{2}-z_{t}\right)$. Restrictions on the volatility function differ more widely, though often a constant elasticity of variance (CEV) specification is adopted, i.e. $\sigma_{z}^{2}\left(z_{t} ; \beta\right)=\sigma^{2} r_{t}^{\beta_{3}}$ where $\beta_{3}=0$ for Vasicek's model, $\beta_{3}=2$ in the model proposed by Courtadon, and $\beta_{3}=1$ for CIR.

In the multi-factor extensions of the term structure the parametric restrictions being imposed are typically of the kind discussed by Duffie and Kan (1996), where a class of compatible models described by the triplet $\left(\mu_{z}, \sigma_{z}, f\right)$ is considered with:

$$
f(z, \tau)=\exp \left[A(\tau)+B(\tau)^{\prime} z\right]
$$

where $A(\tau)$ is a scalar and $B(\tau)$ is a $K \times 1$ vector. This so-called class of affine term structure models implies in particular that equation (5) specializes to:

$$
d r_{\tau t}=\left[B(\tau)^{\prime} \mu_{z}\left(z_{t} ; \beta\right)\right] d t+\left[B(\tau)^{\prime} \sigma_{z}\left(z_{t} ; \beta\right)\right] d W_{t} .
$$

Hence, $d r_{\tau t}$ is determined by a set of common factors $z_{t}$ with a maturity effect which is given by the scaling function $B(\tau)$. Obviously, some elements of $B(\tau)$ may be zero for some $\tau$. Therefore, all factors do not necessarily affect all maturities simultaneously.

Following Chan, Karolyi, Longstaff and Sanders (1992) and others, let us now consider an Euler discretization of (7), namely:

$$
\Delta r_{\tau t+1}=\left[B(\tau)^{\prime} \mu_{z}\left(z_{t} ; \beta\right)\right]+\left[B(\tau)^{\prime} \sigma_{z}\left(z_{t} ; \beta\right)\right] \varepsilon_{t+1} .
$$

where $\varepsilon_{t}$ is i.i.d. $N\left(0, I_{K}\right) .{ }^{5}$ Hence the conditional mean and variance for the interest rate processes are respectively:

$$
E\left(\Delta r_{\tau t+1} \mid z_{t}\right)=\left[B(\tau)^{\prime} \mu_{z}\left(z_{t} ; \beta\right)\right]
$$

whereas the conditional variance is given by:

$$
V\left(\Delta r_{\tau t+1} \mid z_{t}\right)=\left[B(\tau)^{\prime} \sigma_{z}\left(z_{t} ; \beta\right)\right]\left[B(\tau)^{\prime} \sigma_{z}\left(z_{t} ; \beta\right)\right]^{\prime}
$$

The restrictions imposed by the affine term structure model can now be made precise. Let us consider first cases where $B(\tau)$ is nonzero, hence all the factors affect the zero coupon rate at

\footnotetext{
${ }^{5}$ While we proceed here with Euler discretizations it should be noted that the subsequent analysis does not critically depend on this particular choice of discretization. Recently, other discretization schemes have been adopted, see e.g. Tauchen (1996) who used the Platen Strong Order 1 Scheme described in Kloeden and Platen (1992, pp.374-375) to better take into account some of the curvature of the diffusion functions. The impact of different discretization schemes will be discussed shortly.
} 
maturity $\tau$. From (9), we see that the derivatives of the conditional mean with respect to a factor $z_{i t}$ are the same up to a scaling factor that depends on $\tau$. Likewise, the marginal effect of a factor on the conditional variance of interest rates should also be the same up to a scale factor. The affine model thus imposes tight common factor restrictions on both the conditional mean and variance of the term structure. The fact that we have restrictions on the first two conditional moments is quite important and useful for empirical testing. Although the affine term structure restrictions are formulated in terms of the risk-neutral density $Q$ which differs from the empirical data generating process, the common factor representation and the affine structure apply to the risk-neutral as well as the empirical density. ${ }^{6}$ These restrictions across interest rates of different maturities thus provide a set of testable hypotheses which can be used to assess the affine term structure model.

As discussed earlier, not all factors necessarily affect interest rates at all maturities simultaneously under the affine term structure restrictions. In other words, $B(\tau)$ may have zero elements for some given $\tau$. When a factor is excluded at a particular maturity then of course the marginal effects are no longer the same across maturities. However, if a factor is excluded from the conditional mean of an interest rate of a given maturity, it may not necessarily be excluded from the conditional variance of the same interest rate. Indeed, through the off-diagonal elements of the covariance matrix $\sigma_{z}\left(z_{t} ; \beta\right)$ this factor may still appear in the conditional variance although it does not appear in the conditional mean. Fortunately, we can test and identify the presence or absence of a factor to see how many and which factors affect the conditional mean of a particular interest rate.

\section{Estimation Issues}

Our ultimate objective is non-parametric estimation of the conditional mean and variance for the interest rate processes, $E\left(\Delta r_{\tau t+1} \mid z_{t}\right)$ and $V\left(\Delta r_{\tau t+1} \mid z_{t}\right)$ for $\tau$ representing one-month, five-year and ten-year maturities with $z_{t}$ being a set of factors. The zero-coupon interest data used in our empirical application are monthly yields from 1964 to 1990 and taken from McCulloch (1990), for the 1964 to 1983 part of the sample, and Kwon (1992), who extended the original data set from 1983 to 1990 . Hence the sample contains 384 monthly observations.

In practice, our analysis proceeds in two steps. We first identify the factors. Once the factors are identified, we then proceed with estimating the responses of the interest rates to the factors using non-parametric methods. The appeal of non-parametric estimation is that the relationships between interest rates and the factors are completely determined by the data with no distributional

\footnotetext{
${ }^{6}$ The affine structure is a restriction on the relation among random variables which is not affected by the change of measure.
} 
or functional restrictions imposed. This allows us to test the restrictions imposed by the affine model.

We consider two sets of factors. The first set is comprised of two interest rate spreads. This is a fairly conventional way to proceed, using two factors which are directly observable. We will provide more details later on the choice of the spread factors. More unconventional is the second set of factors, one real and one nominal, which are based on macroeconomic variables. This approach has some features in common with the $A P T$ models initially developed for equity pricing by Chen, Roll and Ross (1986), among many others. In the next subsection, we discuss the econometric methodology used to construct the real and the nominal factor. Once this is accomplished, the following section discusses how the response of interest rates to the factors are estimated.

\subsection{Constructing the Real and Nominal Factors}

We are interested in explaining interest rate movements using factors based on macroeconomic variables other than interest rates. This is motivated by the fact that although interest rate spreads might capture the dynamics of interest rate movements, the use of the spreads as factors does not shed light on the relationship between economic conditions and interest rates. Possible candidates for the variables underlying the macroeconomic factors are interest-sensitive series such as industrial output, money growth and inflation. These variables, which we denote as $x$, can be motivated by many macroeconomic paradigms (e.g. the IS-LM model). But, because there is no theory on which to guide the grouping of the variables into factors, we need an estimation strategy that gives us a set of factors with a meaningful economic interpretation. For example, a linear combination of housing starts and the exchange rate would not be an economically interesting factor. Our choice of factors is therefore based upon casual economic reasoning.

Since interest rates provide the link between the real and the financial side of the economy we expect them to be affected by real and monetary factors. This being the case, our goal is to construct a nominal and a real factor. Partitioning the matrix $x$ into $x_{1}$ (the nominal variables) and $x_{2}$ (the real variables), we have two indices $z_{1}=x_{1}^{\prime} \delta_{1}$ and $z_{2}=x_{2}^{\prime} \delta_{2}$ where $\delta_{1}$ and $\delta_{2}$ are factor loadings. ${ }^{7}$ The factor loadings of $z_{i}$ are obtained from the estimation of $y$ conditional on $x_{1}$ and $x_{2}$ using the indirect slope estimator, $\delta$, defined empirically as:

$$
\hat{\delta}=S_{l x}^{-1} S_{l y}
$$

where $S_{l z}=N^{-1} \sum l\left(x_{i}\right)\left(z_{i}-\bar{z}\right) 1_{i}, \hat{l}(x)=\hat{f}^{\prime}(x) / \hat{f}(x)$ is the score, $f(x)$ is the density. Because

\footnotetext{
${ }^{7}$ To avoid cumbersome notation in the remainder of this section we shall denote the dependent variables such as $\Delta r_{\tau t+1}$ or its volatility by $y$ and drop the time indices from the factors $z_{i t}$.
} 
numerical problems can arise when $\hat{f}(x)$ is too small, the density is trimmed at the $5 \%$ level, a condition determined by the the indicator variable $1_{i}$. The indirect slope estimator is an "average derivative estimator" considered in Powell, Stock and Stoker (1989). ${ }^{8}$ The estimator can also be viewed as an instrumental variable estimator using the scores as instruments. ${ }^{9}$ The scores are proportional to the matrix $x$ if the true relationship between $y$ and $x$ is indeed linear, in which case, $\hat{\delta}$ reduces to OLS. The estimator is $\sqrt{N}$ consistent if $x$ and the regression error are i.i.d. and the asymptotic properties of the estimator are analyzed in Stoker (1991). It is worth noting here that even though $z_{i}$ is a generated regressor, since we replace $x_{i}^{\prime} \delta_{i}$ by $x_{i}^{\prime} \hat{\delta}_{i}$ model achieves pointwise consistency at the rate $N^{2 / 5}$ as though $\hat{\delta}$ is known. ${ }^{10}$

Because of the time series nature of our application, the possibility is high that the i.i.d. assumption is violated. Fortunately, in a recent paper by Chen and Shen (1996), the estimator was shown to achieve a convergence rate of $\sqrt{N}$ under the assumption that $x_{t}$ (the regressors) and the regression error are stationary uniform mixing. However, the estimated covariance matrix of the average derivatives needs to take the weakly dependent nature of the errors into account. Let $r_{u}=$ $y-x^{\prime} \hat{\delta}$, where $\hat{\delta}$ are the estimated average derivatives. In our analysis, $S_{r_{u} r_{u}}$ is the heteroskedasticautocorrelation consistent variance covariance matrix using the Parzen window with automatic selection of the bandwidth as discussed in Andrews (1991). Since the $r_{u i}$ are prewhitened and recolored by a first order VAR, it amounts to using the procedure proposed by Andrews and Monahan (1992). That is, the variance-covariance matrix of $(\hat{\delta}-\delta)$ is computed from

$$
\begin{aligned}
\hat{u}_{i} & =\left(y_{i}-\bar{y}\right)-\left(x_{i}-\bar{x}\right)^{\prime} \hat{\delta} \\
r_{u i} & =\hat{l}\left(x_{i}\right) \hat{1}_{i} \hat{u}_{i}+N^{-1} h^{-k} \sum_{j=1}^{N}\left[h^{-1} K^{\prime}\left(\frac{x_{i}-x_{j}}{h}\right)-K\left(\frac{x_{1}-x_{j}}{h}\right) \hat{l}\left(x_{j}\right)\right] \frac{\hat{1}_{j} \hat{u}_{j}}{\hat{f}\left(x_{j}\right)} \\
\hat{\Omega} & =S_{l x}^{-1} S_{r_{u} r_{u}} S_{l x}^{-1} .
\end{aligned}
$$

where $K$ is a kernel function and $h$ is the bandwidth. To proceed with the choice of bandwidth in estimating the average derivatives we standardize all the variables to have a mean of zero and a unit variance. The same bandwidth $h$ can then be used to evaluate the multidimensional kernel function because it is invariant to the scale of the variables:

$$
K\left(u_{1} \ldots u_{k}\right)=\prod_{i=1}^{k} \kappa\left(u_{i}\right)
$$

\footnotetext{
${ }^{8}$ Stoker (1993), for example, has considered single index models with the weights of the index based on estimates of the indirect slope estimator. What is often referred to as "factor models" in the finance literature is thus "index models" in the semi-parametric and other literatures, and we will on occasions use the two terms interchangeably.

${ }^{9}$ The advantage of the indirect slope estimator over the alternative average derivative estimators is that the smoothing required on both the numerator and denominator of $\hat{\delta}$ reduces the smoothing bias that arises in finite samples (see Stoker (1993)).

${ }^{10}$ See Theorem 10.4.2 of Härdle (1990).
} 


$$
\text { where } \quad \kappa\left(u_{i}\right)=\frac{1}{\sqrt{2 \pi}} \exp \left(-u_{i}^{2} / 2\right)
$$

The bandwidth is obtained as the plug-in value based on equation (4.14) of Powell and Stoker (1992). For the sample size and number of regressors used in the analysis, we settle for a bandwidth of 0.7 . Results with $h=1$ and .5 were quite similar.

Our estimation of average derivatives involves seven variables (all lagged one period): growth of M2, the first difference of the (log) exchange rate between the U.S. and the U.K., the annual rate of inflation, changes in (log) industrial production, changes in (log) housing starts, changes in $(\log )$ real retail sales and finally changes in finished goods inventories. ${ }^{11}$ All the series are seasonally adjusted and were retrieved from Citibase ${ }^{12}$. The sample period is 1964-1990. Hence, they are standard series used in US empirical macroeconomic studies. The nominal index factor is constructed using the first three series, while the real factor is based on a combination of the last four.

We present in Table 1 the ADE estimates with two types of $t$ statistics. These are based on two sets of standard errors estimates, the first are valid under i.i.d. while the second involves a heteroskedasticity and autocorrelation consistent estimation procedure. As a matter of comparison we also report the OLS estimates and their $t$ statistics for the parameter estimates.

Let us first discuss the results by examining what the parameter estimates for each of the three regressions yielded. The results in Table 1 show that the effect of money growth is positive, as expected, but is statistically not significant for all of the three maturities. Hence, one could argue that it does not appear to be part of the nominal fundamental factor (with the other two series being present). The foreign exchange variable is significant only for the five-year bond, and the estimate is numerically different from the two other maturities. The inflation rate is highly significant for all maturities and roughly equal across the five-year and ten-year bonds. The unconstrained ADE estimates suggest inflation has a much bigger impact on the short end of the term structure.

The next four parameter estimates form the real index factor. The first three variables underlying the real index series all have a positive impact. The impact of retail sales changes on the short rate appears not to be significant, however. Housing starts and changes in inventories on the other hand seem to have a significant short term impact which becomes less significant at the longer maturities. The impact of inventory changes is negative on interest rate changes, as expected. However, the effect of inventories on the short-term rate is insignificant. These estimates reveal that real economic variables found to have explanatory power for the short term rate do not necessarily have explanatory power for the longer term maturities and vice versa. Indeed, the

\footnotetext{
${ }^{11}$ The mean of the series are $6.91,-1.31,5.44,3.12,-1.28,1.02$, and 1.22 respectively.

${ }^{12}$ The relevant Citibase variables are fym2, exrur, pzunew, ip, hsfr, rtrr, ivmt82.
} 
real and nominal variables used here are more capable of explaining the longer term maturities. While the search is not exhaustive, experimentation with other explanatory variables lead to the same general conclusion that the average derivatives are better determined in the equations for the longer term maturities than the short term rate.

Notice that the OLS estimates are larger for money growth and generally smaller for the exchange rate compared to the $\mathrm{ADE}$ estimates. The ADE estimates for inflation are much larger than the OLS estimates. For the real variables, we also observe some noticeable differences between OLS and ADE parameter estimates. The discrepancies between the two sets of estimates suggest some departure from normality and/or linearity in the true relationship between interest rates and the macroeconomic variables. More importantly, the ADE estimates are statistically better determined than the OLS estimates.

Using the average derivatives as weights, we constructed the real factor as a function of changes in industrial production, retail sales, housing starts, and inventories. Likewise we constructed the nominal factor index applying the ADE weights on money growth, the exchange rate and the inflation rate. A total of six indices are thus constructed, as there are three different maturities of interest rates being modeled. In Figure 1 we plot the six index series.

Recall that the term structure models purport to explain zero coupon bond pricing at different maturities through a set of common factors. The fact that we have three real factors and an equal number of nominal ones rather than one real and nominal factor raises a number of issues we need to discuss. The problem is that the ADE estimation procedure does not easily extend to multivariate settings where a single index or a pair of indices can be estimated via a simultaneous equation system. But one would expect that if there are indeed common factors driving the interest rates, we should roughly come to the same factors whether we estimate the factor loadings with or without restrictions across maturities. We can to a certain extent view this as a first informal test of the common factor estimates.

The results in Figure 1 indeed reveal that the two factors for the different maturities have similar dynamics in general, even though we have not imposed restrictions across maturities during the estimation. In Table 2 we report the cross-correlations between the six index series. We find very high correlations across the three real indices constructed separately from each of the three different maturities. Likewise, the correlations across the three nominal indices are also very close to one. The fact that the cross-correlations between the real and nominal factors are typically small is also a reassuring result. In the remainder of the paper we will treat the three maturities separately with their respective factors as they appear in Figure 1. This is a statistically inefficient way to proceed as we would have preferred to handle one common set of estimates for the real and 
nominal factor. The strong similarity across the factors shows that we are not very much off target by proceeding with single equation methods. Moreover, the similarity is supportive of a common factor specification which we uncovered without being specific about the response function. To find out whether this response function is within the class of affine structures will be a matter of hypothesis testing.

To put the real and nominal factors which we identified into perspective, we consider them alongside with the interest rate spread factors. For the three maturities considered we can in principle construct three spreads as factors, these are spreads between the one month and the five year rate (henceforth $1 M / 5 Y$ ), between the one month and ten year rate (henceforth $1 M / 10 Y$ ), and between the five and the ten year rate (henceforth $5 Y / 10 Y$ ). They appear in Figure 2. We note that the $1 M / 5 Y$ spread is strongly correlated with the $1 M / 10 Y$ spread with a correlation of ..98. However, the correlation between the $1 M / 5 Y$ and $5 Y / 10 Y$ spreads is much weaker (.57). We will therefore select the two least correlated spreads as factors, namely the one month and five year and the five year and ten year spreads as factors. It is also worth noting that the correlations between the spreads and the real and nominal factors have correlations that do not exceed .3.

\section{Modeling the Response of Interest Rates to the Factors}

We continue to focus on econometric models which do not require us to be explicit about the functional form for $B(\tau)^{\prime} \mu_{z}\left(z_{t} ; \beta\right)$. As noted earlier, standard interest rate models differ with regard to the choice of the compatible set of functions $\left(\mu_{z}, \sigma_{z}, A, B\right)$. We will try to be agnostic about this by adopting functions of flexible form for both the conditional mean and the conditional variance. Specifically, $B(\tau) \mu_{z}\left(z_{t} ; \beta\right)$ for different values of $\tau$ are specified as polynomials in the factors. Polynomial regressions provide non-parametric approximations to the true regression functions, as controlled by the order of the polynomials, but can be estimated by least squares. A polynomial regression of order $p$ in each of the two indices takes the form:

$$
\Delta r_{t+1}=\alpha_{0}+\sum_{i=1}^{p} \alpha_{1 i} z_{1 t}^{i}+\sum_{i=1}^{p} \alpha_{2 i} z_{2 t}^{i}+\epsilon_{t}
$$

Polynomial regressions have the distinct advantage over a spline approximation to $B(\tau) \mu_{z}\left(z_{t} ; \beta\right)$ in that the marginal effect of $x_{i}$ on $y$ can be calculated immediately. That is to say, if $z_{1}=x_{i}^{\prime} \delta_{1}$ and $z_{2}=x_{2}^{\prime} \delta_{2}$ are index variables based on a set of variables $x, \partial y / \partial x_{j}$ can be calculated as $\sum_{i=1}^{p}\left(\alpha_{i 1} \delta_{1 j}^{i}\right)+\sum_{i=1}^{p}\left(\alpha_{i 2} \delta_{2 j}^{i}\right)$, where $\delta_{1 j}=\partial z_{1} / \partial x_{j}$ are the weights of $x_{j}$ in index $z_{1}$ as determined by the estimates of the average derivatives. A similar interpretation holds for $\delta_{2 j}$. Polynomial regressions have the additional advantage in the present setting in view of the fact that our empirical models for the conditional mean and variance are based on the Euler discretizations of (5) leading 
to (9) and (10). Discretization biases are well known in parametric specifications. The biases are the higher order terms from the Taylor series expansion of (5) and hence are powers of $z$. Thus, expressing the conditional mean and variance of $\Delta r_{t+1}$ as polynomials in $z_{t}$ also enables the specification to pick up discretization bias terms which could be empirically non-negligible.

In the polynomial regressions, the two factors are either the real and nominal factors, or the interest rate spreads. Note that the timing of the variables follows from the Euler discretization and in turn implies that $z_{t}$ are predetermined as far as $\Delta r_{t+1}$ is concerned, so that the issue of simultaneity bias does not arise. The regression model (13) is of the form $y_{t}=\alpha+\phi_{1}\left(z_{1}\right)+\phi_{2}\left(z_{2}\right)$ and is thus a General Additive Model [see Hastie and Tibshirani (1990)]. Our analysis being on interest rates, one would generally expect the equations for the conditional mean and variance to have some dynamic structure. As discussed in Chen and Tsay (1993), estimation of general additive autoregressive models is still asymptotically valid when time series data are used, although some additional care must be taken to avoid spurious fitting of additive autoregressive models in finite samples. ${ }^{13}$ One interesting aspect of our results is that an autoregressive structure appears unnecessary. There are two explanations to the simple dynamics of our model. First, all the variables enter in the form of first differences or functions of first differences, and first differencing removes the persistent components in the data. Second, it is possible that the non-linear terms in $z_{t}$ picked up what would otherwise have been explained by the linear dynamic terms. Thus, in spite of the remarkably simple dynamic structure, we found and will report in the next section that the Box-Ljung statistic cannot reject the hypothesis that the estimated residuals of the conditional mean equations are white noise.

\section{Testing the Affine Structure}

In section 2 we derived a set of restrictions for a general affine term structure model without specifying the factor response dynamics. We noted that not all factors should simultaneously affect each of the maturities of the term structure. Moreover, we also found that if a factor affects two different maturities then the derivative of changes in the conditional mean of interest rates with respect to the factor should be the same across maturities. Moreover, for the conditional variance we obtained the same type of restrictions when all factors are simultaneously present. ${ }^{14}$ These restrictions can easily be determined by the degree of the polynomial approximation. More specifically, we should observe the following features if the affine structure is correct. First, a factor

\footnotetext{
${ }^{13}$ The problem arises because a bad fit on $\left(\hat{x}_{t-1}\right)$ has a direct impact on the dependent variable in the next step of the backfitting algorithm. For this reason, we make no attempt to fit additive autoregressive models in this analysis.

${ }^{14}$ Restrictions on the conditional variance models when some elements of $B(\tau)$ are zero will be discussed shortly.
} 
found significant in the conditional mean regression should also be significant in conditional variance regression (though the degree of the polynomial could be different). ${ }^{15}$ Second, if a factor affects two interest rates, the two interest rates should have polynomials in the factor of the same degree (again the degree of the polynomial for the conditional mean and that for the conditional variance may differ). We investigate these restrictions with the different factor specifications, beginning with the real and nominal ones. In the final subsection we assess the robustness of our findings through various diagnostics.

\subsection{Using the Real and Nominal Factors}

We first turn to the results using the real and nominal factors. The empirical results pertaining to the conditional mean equations appear in Table 3. There are two parts to the table. The top part reports the polynomials for the conditional means where the degrees of the polynomial regressions are kept the same across maturities as would be predicted from the affine term structure restrictions. These are called unconstrained estimates in the sense that they include what appears to be insignificant regressors. We also report in the lower part of the table regression results selected by the AIC for picking the order of the polynomials. ${ }^{16}$ The same type of exercise is done for the conditional variance and will be discussed shortly.

The results in Table 3 show that the real factor requires at most a second order polynomial, while the nominal factor requires only a linear one. Furthermore the linear term for the nominal factor does not enter significantly in the shortest maturity, since a $t$ statistic of only 1.499 is obtained. Under the affine term structure one should expect a linear term to be present in the one month rate since the linear term appears quite significantly in both the five and ten year bonds. But the data suggest that only a single real factor affects the short rate while both nominal and real factors affect the long maturity rates. Another difference between the top and lower panel of Table 3 is the quadratic term in the real factor affecting the five year maturity rate. The $t$ statistic is borderline with a value of 2.172 and the AIC criteria in fact select the lower order linear polynomial specification appearing in the second panel of the table. These first results appear to suggest some departures from the affine term structure restrictions.

One could argue that the non-significant nominal factor in the one month rate is not in conflict with the affine term structure specification since it simply has a zero loading factor. Moreover, one could argue that the borderline $t$ statistic for the five year rate implies one still should include a quadratic term. Hence, so far the evidence against the affine term structure restrictions is

\footnotetext{
${ }^{15}$ It should be noted that the converse is not necessarily true, namely a factor may not enter the conditional mean for a given $\tau$ but nevertheless affect the conditional variance.

${ }^{16}$ We also considered the BIC and the criterion usually selects the same model.
} 
inconclusive. We need to rely on the conditional second moment conditions to further assess the restrictions.

To analyze the conditional variance we took the residuals of the conditional mean regressions and squared them; these are then used as the dependent variable of the conditonal variance regressions. The estimates appear in the lower part of Table 4. For each maturity the same real and nominal factors are used in the conditional mean and variance regressions. Obviously we first need to assure ourselves that the residuals of the conditional mean regressions are indeed uncorrelated. To assess this we reproduce the autocorrelation functions in Figure 3. The left panel pertains to the residuals of the conditional mean regression, the right one pertains to the square of these residuals. The figure shows that none of the residuals are autocorrelated. This is quite remarkable as it suggests that all temporal linear dependence was removed despite the fact that no lagged interest rate was put into the polynomial regressions. Hence the residuals were whitened by a combination of the nonlinearity and the factors. However, there is clear evidence of persistence in the squared residuals.

According to the results appearing in Table 4 we need a linear polynomial in the real and nominal index for the conditional variance regression for the one-month rate. Yet, for the five and ten year maturities, linear and higher order terms of the real factor are insignificant. Hence for yields of longer maturties the conditional volatility is entirely driven by the nominal factor. This result is at odds with the affine model because if the affine model is correct, the real factor should affect the conditional variance of all three rates as it did so for the conditional mean. ${ }^{17}$ Note, however, that even though the nomianl rate appears in the conditioanl variance of the one month rate but not in the conditonal mean, the result is consistent with the affine model. As discussed earlier, the factors can affect the conditonal variance through the off-diagonal elements of $\sigma_{z}$. What is inconsistent with the theory is the finding that the factors affect the conditional mean but does not affect the conditional variance.

The combination of the empirical evidence retrieved from the conditional mean and variance equations suggests rather strongly that the affine term structure restrictions do not hold up against the data. Although our main focus is to test these restrictions it may parenthetically be noted that some authors have restricted affine bond pricing models to have affine drift and volatility functions $\tilde{\mu}_{z}\left(z_{t} ; \beta\right)$ and $\sigma_{z}\left(z_{t} ; \beta\right) .{ }^{18}$ The results in Table 3 clearly indicate that such restrictions on the drift function are unwarranted. However, the results in Table 4 suggests that it can be applied to the conditional variance.

\footnotetext{
${ }^{17}$ Indeed, if the real factor is deleted from the conditional variance then the $B(\tau)$ vector should also zero out the real factor in the conditional mean, since the conditional mean and variance of a given maturity should be affected by the same factors according to (9) and (10).

${ }^{18}$ Dai and Singleton (1997) for instance focus exclusively in this restrictive class of affine models.
} 


\subsection{Using the Spread Factors}

Let us turn now to the second model specification involving the interest rate spreads. We have again two factors, namely the one month to five year spread and the five year to ten year spread. The conditional mean is covered in Table 5. The constrained estimates obtained from the AIC criteria (and $t$ statistics) choose a linear response to the first factor only for the two long term maturities. However, the $1 M / 5 Y$ spread does not enter significantly as a factor of the one month rate. Conversely, the $5 Y / 10 Y$ spread has a response function which is quadratic for the one month rate while it is only linear for the two long term maturities. Hence, we uncover again rather strong violations against the affine structure restrictions with spreads as factors. For the conditional variance regressions, the unconstrained and constrained models coincide, hence the top and lower panels are identical. The $1 M / 5 Y$ spread does not enter significantly at all in the five and ten year conditional volatility equations. This finding is not in line with the affine term structure specification as it does not agree with the conditional mean results. A final comment, which also leads into the next section where we report diagnostics, is that the adjusted $R^{2}$ of the regressions in Tables 5 and 6 involving the spread factors are generally higher compared to the real and nominal factor specifications discussed in the previous section.

\subsection{Diagnostics}

How robust are the results we reported so far? How much do they depend on the factor specification? Are the real and nominal factors an adequate representation vis-à-vis the spread factor specifications and vice versa? In this section we investigate the robustness of our findings. We begin with the real and nominal factor models appearing in Table 3, expanding the original specification along several lines.

The top panel of Table 7 reports regressions where the conditional mean equations in Table 3 are augmented with lagged real and nominal factors. We find that none of the lagged regressor coefficients appear to be significant. An even stronger results is reported in the next panel of the same table. Adding lagged changes in interest rates for each of the three maturities is not statistically significant either. Hence, we find that the interest rate dynamics are well captured by the original specification covered in Table 3 (cfr. the autocorrelations of residuals plotted in Figure $3)$.

That the interest rates can be explained by a set of macroeconomic factors or a set of spread factors raises the issue of whether either set of factors is adequate. The regression results reported in the lower panel of Table 7 show that the residuals of the conditional mean regressions involving real and nominal factors can still be explained by the two spread factors, at least for the $5 Y$ 
and $10 Y$ rates. These results reveal that the real and nominal factor specification is not entirely adequate, although it seems to capture the temporal dynamics in interest rates. The inadequacy of one set of factors is confirmed by diagnostics applied to the spread factor model. Table 8 reports results of augmenting the spread factor model with real and nominal factors (only the linear terms). The $t$ statistics appearing in Table 8 combined with those in Table 7 reveal that neither of the two factor specifications entertained in the previous section are fully taking into account the information relevant to interest rate modeling.

The significance of spreads in the real and nominal factor model and vice versa prompted us to consider a final specification, involving three factors. Besides the real and nominal factors we constructed a linear combination of the $1 M / 5 Y$ and the $5 Y / 10 Y$ spreads, again using the ADE estimation procedure to estimate the weights of this linear combination. ${ }^{19}$ This allows us to expand the model by a single factor which is a combination of the two spreads rather than adding directly the two supplementary factors.

We report the three factor model results in two final tables, namely Tables 9 and 10. They contain the unconstrained and constrained conditional mean and variances models. Let us start with the conditional mean specifications again. Linear polynomials suffice for the nominal and the spread factors, while a quadratic expansion is necessary for the real factor. These polynomial expansions coincide with those in Table 3 for the real and nominal factors.

Our primary concern is to test whether our rejections of the affine term structure hold up in this expanded model. They clearly do, as can be seen from the evidence of the conditional mean and conditional variance regressions which are reported in Table 10. The polynomial expansions for the conditional mean models do not match up as they should under the affine term structure restrictions. Indeed the real factor enters only linearly in the $1 \mathrm{M}$ rate as opposed to second order in the other two. Moreover, the results for the conditional variance are also showing significant differences between the constrained and unconstrained specifications. Again we observe violations of the affine restrictions: (1) the real factor does not have the same polynomial expansion, and (2) the nominal factor should be significant in the $10 \mathrm{Y}$ rate.

\footnotetext{
${ }^{19}$ To streamline the presentation we refrain here from reporting all the details of the ADE coefficient estimates. With the three index specification we need to re-estimate all the coefficients, including the ones associated with the nominal and real factors. These coefficients are numerically very close to the ones initially obtained and reported in Table 1. Hence, they produced essentially the same factor series. The weights obtained for the spread factor via the ADE procedure are reported as notes to Table 9.
} 


\section{Conclusions}

In this paper we used a semi-parameteric framework to estimate a set of macroeconomic factors for interest rates. These factors, in conjunction with an alternative set of factors based on interest rate spreads, we used to test the restrictions imposed by the affine term structure model. Specifically, we consider i) whether interest rates of different maturities are functions of the factors of the same order, and ii) whether the conditional mean and variance of an interest rate of a given maturity are affected by the same factors. According to our empirical investigation, the affine term structure restrictions are rejected for both sets of factors. Our analysis also shows that the macroeconomic factors have explanatory power for interest rates beyond what is contained in interest rate spreads and vice versa. Thus, although our results are generally supportive of common factors in interest rates (but not the affine structure), they suggest that information would be lost if one relies solely on interset rates of different maturities to model interest rates.

In the introduction of the paper it was noted that many papers have been written on the subject of interest rate movements but with rather limited success so far. The semi-parametric framework used in this paper provides some guidance on what parametric models should try to mimic and aim for improvement through arbitrage and other structural restrictions. The appeal of the semiparametric framework is that it does not require much a priori knowledge of the factors and their responses. The drawback is that in this framework it is difficult to impose arbitrage type conditions across the term structure or other a priori economic restrictions. On this issue, more work remains to be done. 


\section{References}

[1] Aït-Sahalia, Yacine (1996a), "Nonparametric Pricing of Interest Rate Derivative Securities", Econometrica 64, $527-560$.

[2] Aït-Sahalia, Yacine (1996b), "Testing Continuous-Time Models of the Spot Interest Rate", Review of Financial Studies 9, $385-427$.

[3] Andersen, Torben and Lund, Jesper (1996), "Stochastic Volatility and Mean Drift in the Short Term Interest Rate Diffusion: Sources of Steepness, Level and Curvature in the Yield Curve", Discussion Paper Northwestern University.

[4] Andrews, Donald W. K. (1991), "Heteroskedastic and Autocorrelation Consistent Matrix Estimation", Econometrica 59, 817-854.

[5] Andrews, Donald W. K. and Monahan, J. (1992), "An Improved Heteroskedasticity and Autocorrelation Consistent Covariance Matrix Estimator", Econometrica 60, 953-966.

[6] Bansal, Ravi and Viswanathan, S. (1993), "No-arbitrage and and arbitrage pricing: A new approach", Journal of Finance 48, 1231-1262.

[7] Balduzzi, Pierluigi, Das, Sanjiv Ranjan and Foresi, Silverio (1994), "The Central Tendency: A Second Factor in Bond Yields", Discussion Paper, New York University.

[8] Balduzzi, Pierluigi, Das, Sanjiv Ranjan and Foresi, Silverio , "A Simple Approach to Three Factor Affine Term Structure Models", Journal of Fixed Income 6, 43-53.

[9] Chan, K. C., Karolyi, G. Andrew, Longstaff, Francis A. and Sanders, Anthony B. (1992), "An Empirical Comparison of Alternative Models of the Short-Term Interest Rate", Journal of Finance XLVII, 1209-1227.

[10] Chen, Ren Raw and Scott, Louis O. (1993), "Multi-Factor Cox-Ingersoll-Ross Models of the Term Structure: Estimates and Tests from a State-Spate Model using a Kalman Filter", Discussion Paper, Rutgers University and University of Georgia.

[11] Chen, Rong and Tsay, Ruey S. (1993), "Nonlinear Additive ARX Models", Journal of American Statistical Association 88, 955-967.

[12] Chen, Xiaohong and Shen, X. (1996), "Asymptotic Properties of Sieve Extremum Estimates for Weakly Dependent Data with Applications", mimeo, University of Chicago. 
[13] Conley, Timothy, Hansen, Lars P., Luttmer, Erzo and Scheinkman, José (1996), "Estimating Subordinated Diffusions from Discrete Data", Manuscript University of Chicago.

[14] Courtadon, George (1982), "The Pricing of Options on Default-Free Bonds", Journal of Financial and Quantitative Analysis XVII, 75-100.

[15] Cox, John, Ingersoll, Jonathan and Ross, Stephen (1985), "A Theory of the Term Structure of Interest Rates", Econometrica 53, 385-408.

[16] Dai, Qiang and Singleton, Kenneth J. (1997), "Specification Analysis of Affine Term Structure Models", Discussion Paper, Stanford University.

[17] Duffie, Darrell and Kan, Rui (1996), "A Yield-Factor Model of Interest Rates", Mathematical Finance 6, 379-406.

[18] Gallant, Ronald A. and Tauchen, George (1996), "Reprojecting Partially Observed Systems with Applications to Interest Rate Diffusions", Discussion Paper Duke University.

[19] Härdle, Wolfgang (1990), Applied Non-Parametric Regression, Cambridge University Press, Cambridge.

[20] Härdle, Wolfgang and Stoker, Thomas (1989), "Investigating Smooth Multiple Regression by the Method of Average Derivatives", Journal of the American Statistical Association 84, 986995.

[21] Harrison, Micheal and Kreps, David (1979), "Martingales and Arbitrage in Multi-period Security Markets", Journal of Economic Theory 20, 381-408.

[22] Harrison, Micheal and Pliska, Stanley (1981), "Martingales and Stochastic Integrals in the Theory of Continuous Trading", Stochastic Processes and their Applications 11, 215-260.

[23] Hastie, Trevor J. and Tibshirani, Robert J. (1990), Generalized Additive Models, Chapman and Hall, London.

[24] Heath, David, Jarrow, Robert and Morton, Andrew (1992), "Bond Pricing and the Term Structure of Interest Rates", Econometrica 60, 77-106.

[25] Kloeden, Peter E. and Platen, Eckhard (1992), Numerical Solution of Stochastic Differential Equations, Springer Verlag, Heidelberg. 
[26] Kwon, Heon Chul (1992), "The Time Variant Term Premium of Interest Rates", Ohio State University, Economics Department, Ph.D. dissertation.

[27] McCulloch, J. Houston (1990), "U.S. Term Structure Data", 1946-87, Handbook of Monetary Economics 1, 672-715.

[28] Pearson, Neil D. and Sun, Tong Sheng (1994), "Exploiting the Conditional Density in Estimating the Term Structure: An Application to the Cox, Ingersoll and Ross Model", Journal of Finance 49, 1279-1304.

[29] Powell, James and Stoker, Thomas (1992), "Optimal Bandwidth Choice For Density Weighted Averages", mimeo, M.I.T.

[30] Powell, James, Stock, James H. and Stoker, Thomas (1989), "Semiparametric Estimation of Index Coefficients", Econometrica 57, 1403-1430.

[31] Shiller, Robert J. (1990), "The Term Structure of Interest Rates", in Benjamin M. Friedman and Frank H. Hahn (ed.) "Handbook of Monetary Economics", (North Holland, Amsterdam), chapter 13 .

[32] Stambaugh, Robert (1988), "The Information in Forward Rates: Implications for Models of the Term Structure", Journal of Financial Economics 21, 41-70.

[33] Stanton, Richard (1997), "A Nonparametric Model of the Term Structure Dynamics and the Market Price of Interest Rate Risk", Journal of Finance (forthcoming).

[34] Stoker, Thomas (1991), Lectures on Semiparametric Econometrics, Core Lecture Series, Core Foundation, Louvain-La-Neuve.

[35] Stoker, Thomas (1993), "Smoothing Bias in the Measurement of Marginal Effects", Journal of the American Statistical Association 88, 855-863.

[36] Tauchen George (1996), "New Minimum Chi-Square Methods in Empirical Finance", in David M. Kreps and Kenneth F. Wallis (ed.) "Advances in Economics and Econometrics: Theory and Applications - Seventh World Congress, Vol. 3".

[37] Vasicek, Oldrich (1977), "An Equilibrium Characterization of the Term Structure", Journal of Financial Economics 5, 177-188. 
Table 1: Average Derivative and OLS estimates of one-month, five-year and ten-year interest rate model factor indices

\begin{tabular}{|l|cc|cc|cc|}
\hline & One-month & Five-year & \multicolumn{2}{|c|}{ Ten-year } \\
\hline & ADE & OLS & ADE & OLS & ADE & OLS \\
\hline Money & .00673 & .01285 & .00703 & .00978 & .00563 & .00598 \\
& $(1.097)[1.021]$ & $(1.408)$ & $(1.523)[1.520]$ & $(1.780)$ & $(1.229)[1.225]$ & $(1.340)$ \\
\hline Exch. & .00175 & .00311 & .00254 & .00223 & .00162 & .00122 \\
& $(1.476)[1.438]$ & $(2.039)$ & $(2.683)[2.602]$ & $(2.432)$ & $(1.991)[2.201]$ & $(1.640)$ \\
\hline Infl. & .02855 & .00230 & .01797 & .01207 & .01813 & .01220 \\
& $(3.153)[4.004]$ & $(.228)$ & $(2.985)[3.101]$ & $(1.992)$ & $(3.821)[3.849]$ & $(2.480)$ \\
\hline Ind. Pr. & .00854 & .01381 & .00389 & .00451 & .00359 & .00389 \\
& $(2.671)[2.772]$ & $(3.358)$ & $(1.718)[1.647]$ & $(1.823)$ & $(1.915)[1.886]$ & $(1.936)$ \\
\hline Hous. st. & .00068 & .00081 & .00035 & .00020 & .00028 & .00006 \\
& $(2.286)[1.843]$ & $(1.984)$ & $(1.738)[1.403]$ & $(.807)$ & $(1.585)[1.300]$ & $(.285)$ \\
\hline Sales & .00158 & .00199 & .00467 & .00300 & .00350 & .00256 \\
& $(.826)[.916]$ & $(.817)$ & $(3.300)[3.560]$ & $(2.050)$ & $(2.952)[3.087]$ & $(2.154)$ \\
\hline Invent. & -.00815 & -.03183 & -.02429 & -.01727 & -.02892 & -.01597 \\
& $(-.478)[-.527]$ & $(-1.502)$ & $(-2.014)[-2.191]$ & $(-1.354)$ & $(-2.820)[-3.116]$ & $(-1.543)$ \\
\hline
\end{tabular}

Notes: $t$ statistics are in parenthesis. The $t$ statistics corrected for heteroskedasticity using the Andrews and Monahan (1992) procedure are in brackets.

Table 2: Cross-Correlation Matrix Real and Nominal Factors

\begin{tabular}{ccccccc}
\hline \hline & Real1M & Real5Y & Real10Y & Nom.1M & Nom.5Y & Nom.10Y \\
Real1 $M$ & 1.00000 & 0.94684 & 0.95222 & -0.13805 & -0.16333 & -0.14186 \\
Real5Y & 0.94684 & 1.00000 & 0.99368 & -0.05789 & -0.07280 & -0.05314 \\
Real10Y & 0.95222 & 0.99368 & 1.00000 & -0.05308 & -0.07208 & -0.05170 \\
Nom.1M & 0.13805 & -0.05789 & -0.05308 & 1.00000 & 0.78952 & 0.76382 \\
Nom.5Y & 0.16333 & -0.07280 & -0.07208 & 0.78952 & 1.00000 & 0.98542 \\
Nom.10Y & 0.14186 & -0.05314 & -0.05170 & 0.76382 & 0.98542 & 1.00000 \\
\hline \hline
\end{tabular}

Notes: Entries to the table are the cross-correlations between the real and nominal indices appearing in Figure 1. These indices were computed from the ADE estimates appearing in Table 1. 
Table 3: Polynomial regressions with nominal and real factors - Conditional Mean Models

\begin{tabular}{|c|c|c|c|c|c|c|}
\hline \multicolumn{3}{|c|}{ One-month } & \multicolumn{2}{|r|}{ Five-year } & \multicolumn{2}{|r|}{ Ten-year } \\
\hline & real & nominal & real & nominal & real & nominal \\
\hline \multirow[t]{2}{*}{ Degree 0} & -.2570 & - & -.0745 & - & -.0192 & - \\
\hline & $(-3.748)$ & - & $(-.2145)$ & - & $(.779)$ & - \\
\hline \multirow[t]{2}{*}{1} & .7586 & .1328 & .2902 & .2303 & .1809 & .1465 \\
\hline & $(5.643)$ & $(1.499)$ & $(4.269)$ & $(3.492)$ & $(3.700)$ & $(3.221)$ \\
\hline \multirow[t]{2}{*}{2} & -.4143 & - & -.1739 & - & -.1480 & - \\
\hline & $(-2.9600)$ & - & $(-2.172)$ & - & $(-2.541)$ & - \\
\hline \multirow[t]{4}{*}{$\bar{R}^{2}$} & .083 & - & .069 & - & .066 & - \\
\hline & Con & itional Mear & - Constri & ned Estim & tes & \\
\hline & & One-month & & Five-year & & Ten-year \\
\hline & real & nominal & real & nominal & real & nominal \\
\hline \multirow[t]{2}{*}{ Degree 0} & -.2637 & - & -.0246 & - & -.0192 & - \\
\hline & $(-3.845)$ & - & $(-.940)$ & - & $(.7790)$ & - \\
\hline \multirow[t]{2}{*}{1} & .7239 & - & .2463 & .2235 & .1809 & .1465 \\
\hline & $(5.456)$ & - & $(3.772)$ & $(3.373)$ & $(3.700)$ & $(3.221)$ \\
\hline \multirow[t]{2}{*}{2} & -.3916 & - & - & - & -.1480 & - \\
\hline & $(-2.809)$ & - & - & - & $(-2.551)$ & - \\
\hline $\bar{R}^{2}$ & .079 & - & .058 & - & .066 & - \\
\hline
\end{tabular}

Notes: Entries are based on OLS estimation of polynomial regression in (13) with the factors appearing in Figure 1. The $t$ statistics are in parenthesis and computed using the Andrews and Monahan (1992) procedure.

Table 4: Polynomial regressions of nominal and real factors - Conditional Variance Models

Conditional Variance - Unconstrained Estimates

\begin{tabular}{|c|c|c|c|c|c|c|}
\hline \multicolumn{3}{|c|}{ One-month } & \multicolumn{2}{|r|}{ Five-year } & \multicolumn{2}{|r|}{ Ten-year } \\
\hline & real & nominal & real & nominal & real & nominal \\
\hline Degree 0 & .7789 & - & .1981 & - & .1279 & - \\
\hline & $(8.411)$ & - & $(8.905)$ & - & $(10.055)$ & - \\
\hline 1 & -.6685 & -.7085 & -.0763 & .1690 & -.0320 & .0585 \\
\hline & $(-3.054)$ & $(-4.344)$ & $(-1.378)$ & $(3.255)$ & $(-1.038)$ & $(2.245)$ \\
\hline $\bar{R}^{2}$ & .086 & - & .032 & - & .013 & - \\
\hline
\end{tabular}

\begin{tabular}{|c|c|c|c|c|c|c|}
\hline & \multicolumn{2}{|r|}{ One-month } & \multicolumn{2}{|r|}{ Five-year } & \multicolumn{2}{|r|}{ Ten-year } \\
\hline & real & nominal & real & nominal & real & nominal \\
\hline Degree 0 & $\begin{array}{c}.7789 \\
(8.411)\end{array}$ & - & $\begin{array}{c}.1886 \\
(8.714)\end{array}$ & - & $\begin{array}{c}.1264 \\
(10.001)\end{array}$ & - \\
\hline 1 & $\begin{array}{c}-.6685 \\
(-3.054)\end{array}$ & $\begin{array}{l}-.7085 \\
(-4.344)\end{array}$ & - & $\begin{array}{c}.1921 \\
(3.255)\end{array}$ & $\begin{array}{l}- \\
-\end{array}$ & $\begin{array}{c}.0635 \\
(2.245)\end{array}$ \\
\hline $\bar{R}^{2}$ & .086 & - & .029 & - & .012 & - \\
\hline
\end{tabular}


Table 5: Polynomial regressions with spread factors - Conditional Mean Models

Conditional Mean - Unconstrained Estimates

\begin{tabular}{|c|c|c|c|c|c|c|}
\hline & & One-month & & Five-year & & Ten-year \\
\hline & $1 \mathrm{M} / 5 \mathrm{Y}$ & $5 \mathrm{Y} / 10 \mathrm{Y}$ & $1 \mathrm{M} / 5 \mathrm{Y}$ & $5 \mathrm{Y} / 10 \mathrm{Y}$ & $1 \mathrm{M} / 5 \mathrm{Y}$ & $5 \mathrm{Y} / 10 \mathrm{Y}$ \\
\hline Degree 0 & -.1461 & - & -.0249 & - & -.0102 & - \\
\hline & $(-2.586)$ & - & $(-.736)$ & - & $(-.372)$ & - \\
\hline 1 & .0973 & -.4489 & .3063 & -.3102 & .2619 & -.1999 \\
\hline & $(.785)$ & $(-3.476)$ & $(4.120)$ & $(-4.006)$ & $(4.343)$ & $(-3.184)$ \\
\hline 2 & - & -.5103 & - & -.1584 & - & -.1145 \\
\hline & - & $(-3.604)$ & - & $(-1.865)$ & - & $(-1.663)$ \\
\hline $\bar{R}^{2}$ & .071 & 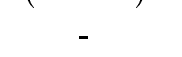 & .065 & - & .059 & - \\
\hline
\end{tabular}

\begin{tabular}{|c|c|c|c|c|c|c|}
\hline \multicolumn{3}{|c|}{ One-month } & \multicolumn{2}{|r|}{ Five-year } & \multicolumn{2}{|r|}{ Ten-year } \\
\hline & $1 \mathrm{M} / 5 \mathrm{Y}$ & $5 \mathrm{Y} / 10 \mathrm{Y}$ & $1 \mathrm{M} / 5 \mathrm{Y}$ & $5 \mathrm{Y} / 10 \mathrm{Y}$ & $1 \mathrm{M} / 5 \mathrm{Y}$ & $5 \mathrm{Y} / 10 \mathrm{Y}$ \\
\hline Degree 0 & -.1517 & - & .0191 & - & .0216 & - \\
\hline & $(-2.706)$ & - & $(.784)$ & - & $(1.905)$ & - \\
\hline 1 & - & -.3912 & .3120 & -.3141 & .2660 & -.2028 \\
\hline & - & $(-3.685)$ & $(4.185)$ & $(-4.042)$ & $(-4.404)$ & $(-3.221)$ \\
\hline 2 & - & -.5149 & - & - & - & - \\
\hline & - & $(-3.642)$ & - & - & - & - \\
\hline $\bar{R}^{2}$ & .072 & - & .057 & - & .053 & - \\
\hline
\end{tabular}

Notes: Details see Table 3. 
Table 6: Polynomial regressions of spread factors - Conditional Variance Models

\begin{tabular}{|c|c|c|c|c|c|c|}
\hline \multicolumn{3}{|c|}{ One-month } & \multicolumn{2}{|r|}{ Five-year } & \multicolumn{2}{|r|}{ Ten-year } \\
\hline & $1 \mathrm{M} / 5 \mathrm{Y}$ & $5 \mathrm{Y} / 10 \mathrm{Y}$ & $1 \mathrm{M} / 5 \mathrm{Y}$ & $5 \mathrm{Y} / 10 \mathrm{Y}$ & $1 \mathrm{M} / 5 \mathrm{Y}$ & $5 \mathrm{Y} / 10 \mathrm{Y}$ \\
\hline Degree 0 & $\begin{array}{c}.8886 \\
(8.897)\end{array}$ & - & $\begin{array}{c}.2895 \\
(9.589)\end{array}$ & - & $\begin{array}{c}.1835 \\
(10.833)\end{array}$ & - \\
\hline 1 & $\begin{array}{l}- \\
-\end{array}$ & $\begin{array}{l}1.0276 \\
(5.432)\end{array}$ & - & $\begin{array}{c}.2077 \\
(3.632)\end{array}$ & - & $\begin{array}{c}.1000 \\
(3.119)\end{array}$ \\
\hline 2 & - & $\begin{array}{l}1.2138 \\
(4.818)\end{array}$ & $\begin{array}{l}- \\
-\end{array}$ & $\begin{array}{c}.3469 \\
(4.556)\end{array}$ & - & $\begin{array}{c}.2098 \\
(4.910)\end{array}$ \\
\hline $\bar{R}^{2}$ & .137 & - & .090 & - & .090 & - \\
\hline
\end{tabular}

\begin{tabular}{|c|c|c|c|c|c|c|}
\hline & \multicolumn{2}{|r|}{ One-month } & \multicolumn{2}{|r|}{ Five-year } & \multicolumn{2}{|r|}{ Ten-year } \\
\hline & $1 \mathrm{M} / 5 \mathrm{Y}$ & $5 \mathrm{Y} / 10 \mathrm{Y}$ & $1 \mathrm{M} / 5 \mathrm{Y}$ & $5 \mathrm{Y} / 10 \mathrm{Y}$ & $1 \mathrm{M} / 5 \mathrm{Y}$ & $5 \mathrm{Y} / 10 \mathrm{Y}$ \\
\hline Degree 0 & $\begin{array}{c}8886 \\
(8.897)\end{array}$ & - & $\begin{array}{c}.2895 \\
(9.589)\end{array}$ & - & $\begin{array}{c}.1835 \\
(10.833)\end{array}$ & - \\
\hline 1 & - & $\begin{array}{l}1.0276 \\
(5.432)\end{array}$ & - & $\begin{array}{c}.2077 \\
(3.632)\end{array}$ & $\begin{array}{l}- \\
-\end{array}$ & $\begin{array}{c}.1000 \\
(3.119)\end{array}$ \\
\hline 2 & - & $\begin{array}{l}1.2138 \\
(4.818)\end{array}$ & - & $\begin{array}{c}.3469 \\
(4.556)\end{array}$ & - & $\begin{array}{c}.2098 \\
(4.910)\end{array}$ \\
\hline $\bar{R}^{2}$ & .137 & - & .090 & - & .090 & - \\
\hline
\end{tabular}

Notes: Details see Table 3. 
Table 7: Diagnostic Regressions for Real and Nominal Conditional Mean Models: Adding Lagged Nominal and Real Factors

\begin{tabular}{|ccc|cc|cc|}
\hline & & One-month & & Five-year & & Ten-year \\
\hline & real & nominal & real & nominal & real & nominal \\
\hline Degree 0 & -.2454 & - & .0208 & - & .0115 & - \\
& $(-2.473)$ & - & $(.448)$ & - & $(.150)$ & - \\
1 & .6915 & - & .2459 & .2622 & .1859 & .1689 \\
& $(5.005)$ & - & $(3.748)$ & $(3.517)$ & $(3.747)$ & $(3.235)$ \\
2 & -.3643 & - & - & - & -.1452 & - \\
& $(-2.545)$ & - & - & - & $(-2.244)$ & - \\
real $_{t-1}$ & .3010 & & .0978 & & -.1331 & \\
& $(.909)$ & & $(.474)$ & & $(-.6814)$ & \\
nominal $_{t-1}$ & -.0451 & & -.3011 & & -.2266 & \\
& $(.1426)$ & & $(-1.125)$ & & $(-.8801)$ & \\
$\bar{R}^{2}$ & .079 & - & .058 & - & .063 & - \\
\hline
\end{tabular}

Adding Lagged Interest Rates

\begin{tabular}{|ccc|cc|cc|}
\hline & & One-month & & Five-year & & Ten-year \\
\hline & real & nominal & real & nominal & real & nominal \\
\hline Degree 0 & -.2626 & - & -.0243 & - & -.0193 & - \\
& $(-3.811)$ & - & $(-.924)$ & - & $(-.778)$ & - \\
1 & .7206 & - & .2422 & .2184 & .1791 & .1434 \\
& $(5.394)$ & - & $(3.666)$ & $(3.244)$ & $(3.628)$ & $(3.077)$ \\
2 & -.3904 & - & - & - & -.1462 & - \\
& $(-2.789)$ & - & - & - & $(-2.464)$ & - \\
$\Delta r_{t-1}$ & .1150 & & .0258 & & .0180 & \\
& $(.2795)$ & - & $(.468)$ & & .324 & \\
$R^{2}$ & .077 & - & .058 & - & .063 & - \\
\hline
\end{tabular}

Adding Spread Factors

\begin{tabular}{|ccc|cc|cc|}
\hline & & One-month & & Five-year & & Ten-year \\
\hline & real & nominal & real & nominal & real & nominal \\
\hline Degree 0 & -.3201 & - & .0522 & - & .0491 & - \\
& $(-4.181)$ & - & $(1.559)$ & - & $(1.630)$ & - \\
1 & .6798 & - & .2730 & .1633 & .2134 & .1061 \\
& $(5.020)$ & - & $(4.197)$ & $(2.494)$ & $(4.361)$ & $(2.336)$ \\
2 & -.3905 & - & - & - & -.1574 & - \\
& $(-2.795)$ & - & - & - & $(-2.729)$ & - \\
$1 M / 5 Y$ & -.0549 & & .1075 & & .0814 & \\
& $(-1.413)$ & & $(4.628)$ & & $(4.296)$ & \\
$5 Y / 10$ & .0073 & & -.3599 & & -.1687 & \\
& $(.0450)$ & & $(-3.737)$ & & $(-2.167)$ & \\
$R^{2}$ & .082 & - & .117 & - & .112 & - \\
\hline
\end{tabular}


Table 8:

Diagnostic Regressions for Spread Factors Conditional Mean Models:

Adding Real and Nominal Factors

\begin{tabular}{|ccc|cc|cc|}
\hline & & One-month & & Five-year & & Ten-year \\
\hline & $1 \mathrm{M} / 5 \mathrm{Y}$ & $1 \mathrm{M} / 10 \mathrm{Y}$ & $5 \mathrm{Y} / 1 \mathrm{M}$ & $5 \mathrm{Y} / 10 \mathrm{Y}$ & $10 \mathrm{Y} / 1 \mathrm{M}$ & $10 \mathrm{Y} / 5 \mathrm{Y}$ \\
\hline Degree 0 & -.1791 & - & -.0538 & - & -.0110 & - \\
& $(-2.170)$ & - & $(-1.094)$ & - & $(-.2587)$ & - \\
1 & 1.6014 & -1.6112 & -.2991 & -.2460 & -.2823 & .2198 \\
& $(2.611)$ & $(-2.775)$ & $(-3.974)$ & $(-4.243)$ & $(3.027)$ & \\
Real & 1.3412 & - & .6495 & & .6104 & \\
& $(4.044)$ & - & $(3.503)$ & - & $(3.425)$ & \\
Nominal & .3430 & - & .6224 & & .5208 & \\
& $(1.0479)$ & - & $(2.209)$ & - & $(1 . .903)$ & \\
$R^{2}$ & .079 & - & .097 & - & .090 & - \\
\hline
\end{tabular}

Table 9: Polynomial regressions with nominal, real and spread factors - Conditional Mean Models Conditional Mean - Unconstrained Estimates

\begin{tabular}{|c|c|c|c|c|c|c|c|c|c|}
\hline & \multicolumn{3}{|c|}{ One-month } & \multicolumn{3}{|c|}{ Five-year } & \multicolumn{3}{|c|}{ Ten-year } \\
\hline & real & nominal & spread & real & nominal & spread & real & nominal & spread \\
\hline \multirow[t]{2}{*}{ Degree 0} & -.3672 & - & - & .0536 & - & - & .0199 & - & - \\
\hline & $(-4.066)$ & - & - & $(1.483)$ & - & - & $(.663)$ & - & - \\
\hline 1 & $\begin{array}{c}.7133 \\
(4.420)\end{array}$ & $\begin{array}{c}.2152 \\
(2.145)\end{array}$ & $\begin{array}{l}-.1374 \\
(-2.361)\end{array}$ & $\begin{array}{c}.2858 \\
(4.767)\end{array}$ & $\begin{array}{c}.1487 \\
(2.801)\end{array}$ & $\begin{array}{c}.7183 \\
(4.578)\end{array}$ & $\begin{array}{c}.2536 \\
(4.894)\end{array}$ & $\begin{array}{c}.1285 \\
(2.920)\end{array}$ & $\begin{array}{c}1.035 \\
(4.846)\end{array}$ \\
\hline \multirow[t]{2}{*}{2} & -.2956 & - & - & -.2002 & - & - & -.1345 & - & - \\
\hline & $(-1.973)$ & - & - & $(-2.863)$ & - & - & $(-2.518)$ & - & \\
\hline \multirow[t]{4}{*}{$\bar{R}^{2}$} & .073 & - & - & .129 & - & - & .120 & - & - \\
\hline & \multicolumn{3}{|c|}{ Conditional } & \multicolumn{6}{|c|}{ Mean - Constrained Estimates } \\
\hline & \multicolumn{3}{|c|}{ One-month } & \multicolumn{3}{|c|}{ Five-year } & \multicolumn{3}{|c|}{ Ten-year } \\
\hline & real & nominal & spread & real & nominal & spread & real & nominal & spread \\
\hline \multirow[t]{2}{*}{ Degree 0} & -.2401 & - & - & .0536 & - & - & .0199 & - & - \\
\hline & $(-3.511)$ & - & - & $(1.483)$ & - & - & $(.663)$ & - & - \\
\hline \multirow[t]{2}{*}{1} & .4920 & - & -1.1360 & .2858 & .1487 & .7183 & .2536 & .1285 & 1.0351 \\
\hline & $(3.763)$ & - & $(-1.971)$ & $(4.767)$ & $(2.801)$ & $(4.578)$ & $(4.894)$ & $(2.920)$ & $(4.846)$ \\
\hline \multirow[t]{2}{*}{2} & - & - & - & -.2002 & - & - & -.1345 & - & - \\
\hline & - & - & - & $(-2.863)$ & - & - & $(-2.518)$ & - & - \\
\hline $\bar{R}^{2}$ & .055 & - & - & .129 & - & - & .120 & - & - \\
\hline
\end{tabular}

Notes: The spread factor is obtained from the following ADE estimates: for one-month .0622(1M/5Y) $.0520(\mathrm{Y} 5 / 10 \mathrm{Y})$, for five-years $.14552(1 \mathrm{M} / 5 \mathrm{Y})-.27487(5 \mathrm{Y} / 10 \mathrm{Y})$, for ten-years $-.08417(1 \mathrm{M} / 5 \mathrm{Y})-.12996(5 \mathrm{Y} / 10 \mathrm{Y})$. The correlations of the three factors exceed .96. All other entries are as in Table 1. 
Table 10: Polynomial regressions with nominal, real and spread factors - Conditional Variance Models

Conditional Variance - Unconstrained Estimates

\begin{tabular}{|cccc|ccc|ccc|}
\hline & \multicolumn{3}{c}{ One-month } & \multicolumn{3}{c|}{ Five-year } & \multicolumn{3}{c|}{ Ten-year } \\
\hline & real & nominal & spread & real & nominal & spread & real & nominal & spread \\
\hline Degree 0 & .9025 & - & - & .2190 & - & - & .1283 & - & - \\
& $(4.865)$ & - & - & $(7.968)$ & - & - & $(7.267)$ & - & - \\
1 & -.2795 & .5345 & 2.063 & -.1973 & .1258 & .0065 & -.0830 & .0302 & -.1133 \\
& $(-.8038)$ & $(2.656)$ & $(1.768)$ & $(-3.955)$ & $(3.131)$ & $(.055)$ & $(2.499)$ & $(1.117)$ & $(-.863)$ \\
2 & -.3539 & - & - & .1436 & - & - & .0381 & - & - \\
& $(-1.059)$ & - & - & $(2.716)$ & - & - & $(1.112)$ & - & - \\
3 & .6858 & - & - & -.2186 & - & - & -.0326 & - & - \\
& $(2.466)$ & - & - & $(-3.976)$ & - & - & $(-1.020)$ & - & - \\
$\bar{R}^{2}$ & .067 & - & - & .099 & - & - & .009 & - & - \\
\hline
\end{tabular}

\begin{tabular}{|ccccc|ccc|ccc|}
\hline \multicolumn{10}{c|}{ Conditional Mean - Constrained Estimates } \\
\hline & \multicolumn{3}{c}{} & One-month & \multicolumn{3}{c|}{ Five-year } & \multicolumn{3}{c|}{ Ten-year } \\
\hline Degree & 0 & .7596 & nominal & spread & real & nominal & spread & real & nominal & spread \\
& $(6.734)$ & - & - & .2190 & - & - & .1176 & - & - \\
1 & - & .6951 & 2.5845 & -.1973 & .1258 & .0065 & -.0619 & - & -.1036 \\
& - & $(3.478)$ & $(2.229)$ & $(-3.955)$ & $(3.131)$ & $(.055)$ & $(2.147)$ & - & $(-.719)$ \\
2 & - & - & - & .1436 & - & - & - & - & - \\
& - & - & - & $(2.716)$ & - & - & - & - & - \\
3 & - & - & - & -.2186 & - & - & - & - & - \\
& - & - & - & $(-3.976)$ & - & - & - & - & - \\
$\bar{R}^{2}$ & .056 & - & - & .099 & - & - & .008 & - & - \\
\hline
\end{tabular}

Notes: The spread factor is obtained from the following ADE estimates: for one-month $.0622(1 \mathrm{M} / 5 \mathrm{Y})$ $-.0520(\mathrm{Y} 5 / 10 \mathrm{Y})$, for five-years $.14552(1 \mathrm{M} / 5 \mathrm{Y})-.27487(5 \mathrm{Y} / 10 \mathrm{Y})$, for ten-years $-.08417(1 \mathrm{M} / 5 \mathrm{Y})-.12996(5 \mathrm{Y} / 10 \mathrm{Y})$.

The correlations of the three factors exceed .96. All other entries are as in Table 1. 

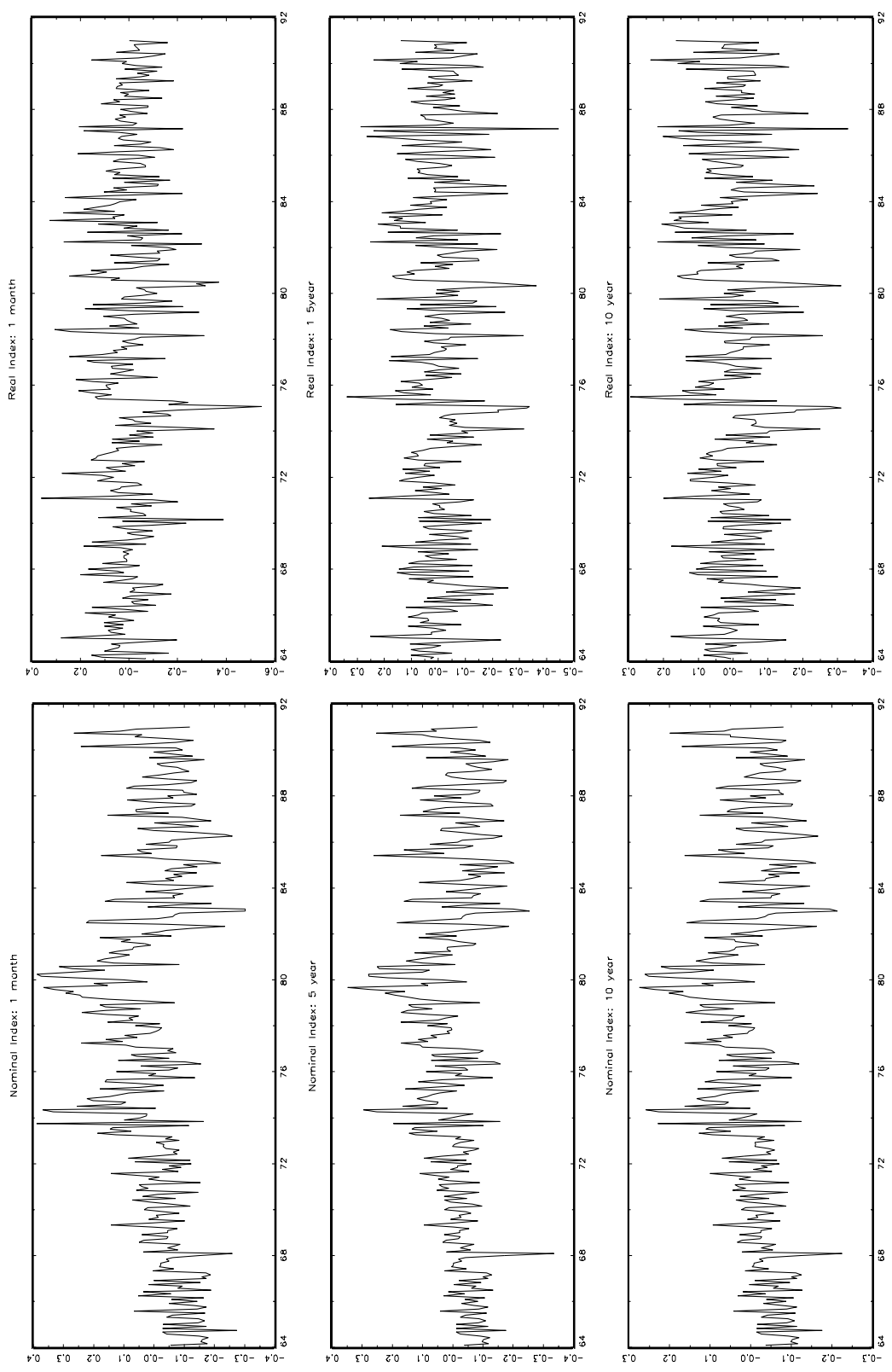

Figure 1: Time Series Plots of Nominal and Real Factors in 1-month, 5-year and 10-year interest rate models using ADE Regression estimates 

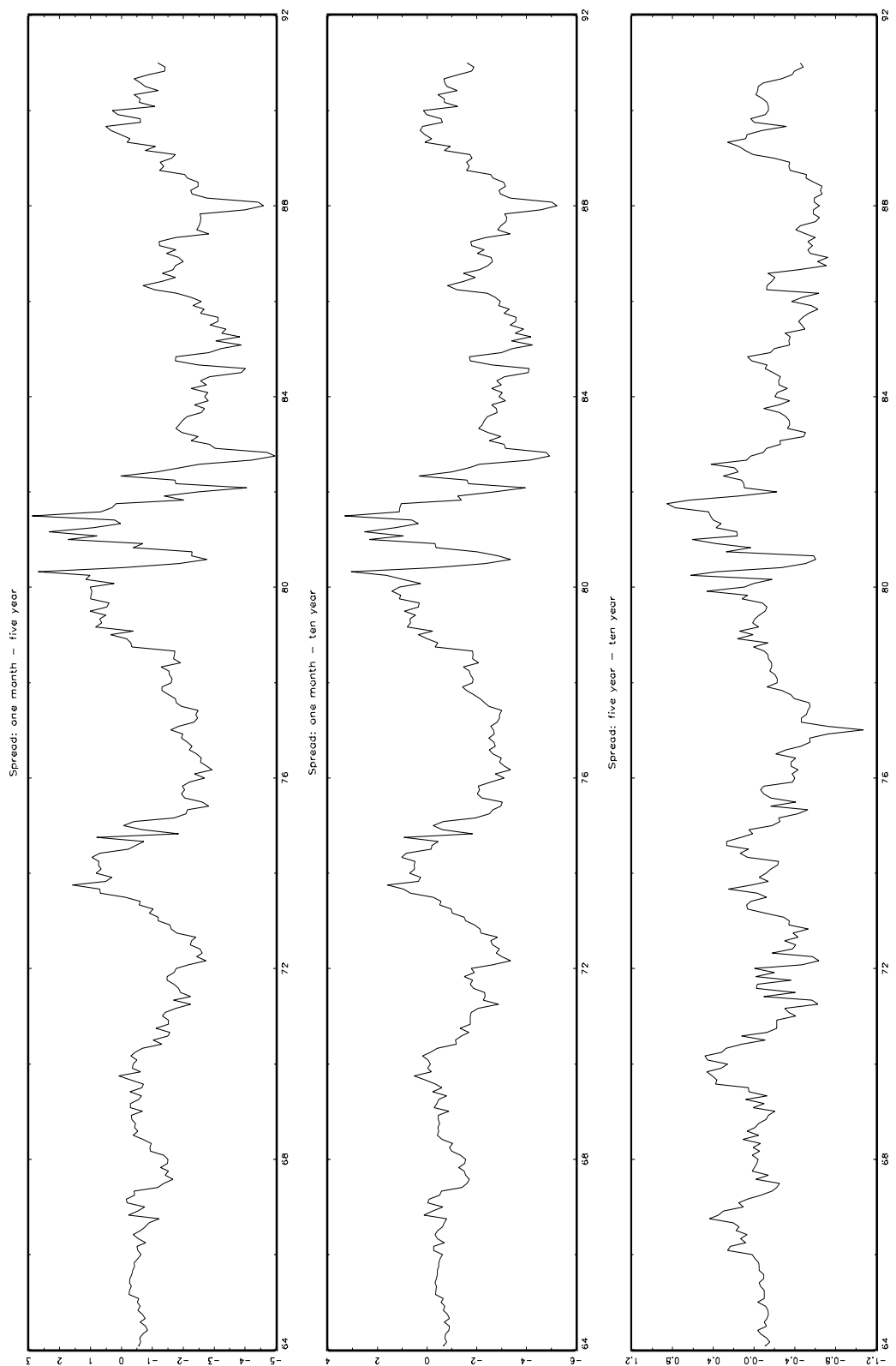

Figure 2: Time Series Plots of Interest Rate Spreads: 1-month - 5 year, 1-month - 10 year, and 5-year - 10-year Regression estimates 

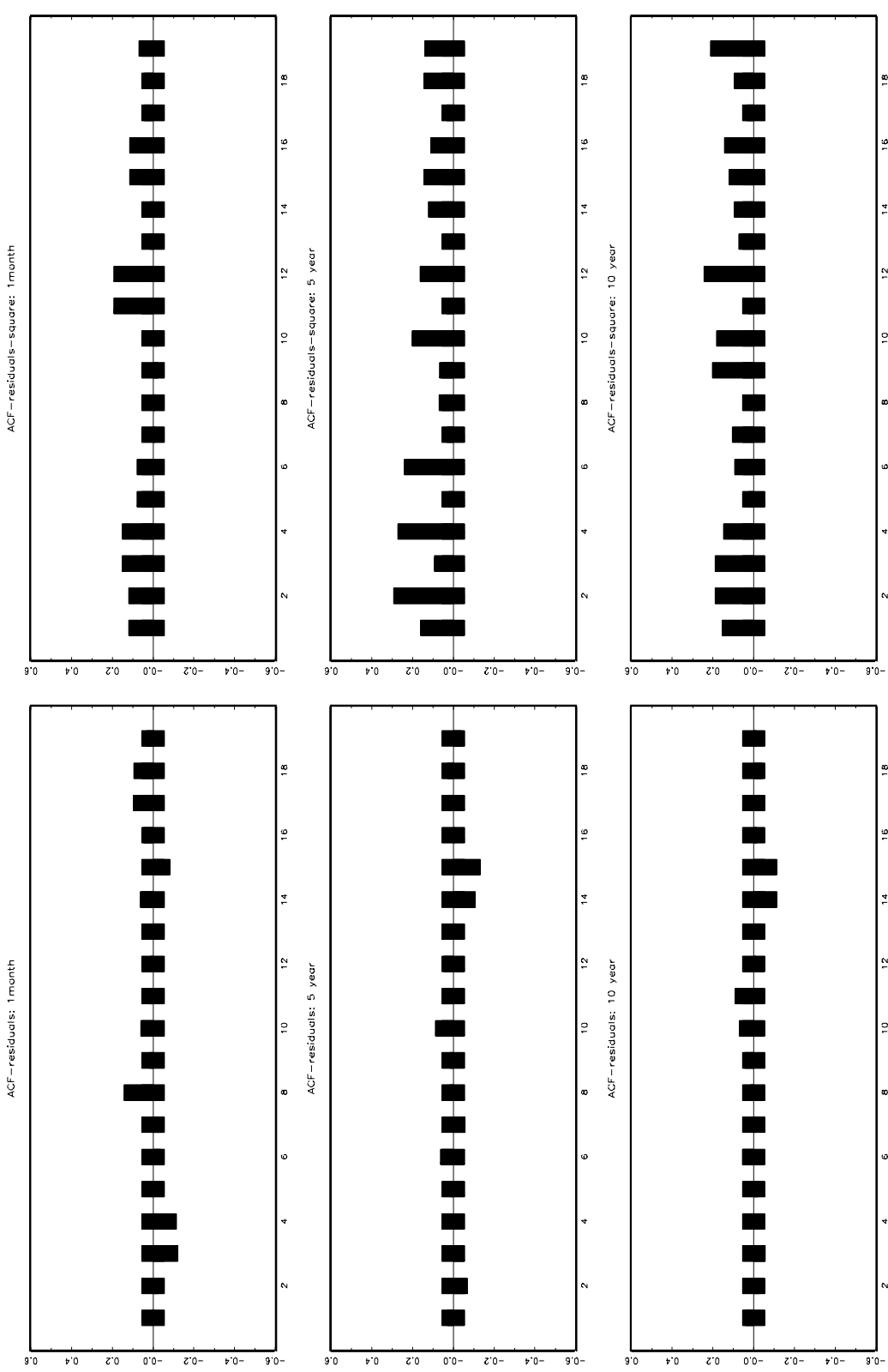

Figure 3: Residual Autocorrelations of Factor Polynomial Regression Models 